\title{
Pediatric Febrile Urinary Tract Infection Caused by ESBL Producing Enterobacteriaceae Species
}

\author{
Asnakech Agegnehu, ${ }^{1}$ Mesfin Worku, ${ }^{2}$ Demiss Nigussie, ${ }^{3}$ Birhanu Lulu, ${ }^{1}$ \\ and Birkneh Tilahun Tadesse $\mathbb{D}^{4}$ \\ ${ }^{1}$ Microbiology Laboratory, Hawassa University Comprehensive Specialized Hospital, Ethiopia \\ ${ }^{2}$ School of Medical Laboratory Science, College of Medicine and Health Sciences, Hawassa University, Ethiopia \\ ${ }^{3}$ Department of Medical Laboratory Science, College of Medicine, Medicine and Health Sciences institute, \\ Debrebirhan University, Ethiopia \\ ${ }^{4}$ Department of Pediatrics, School of Medicine, College of Medicine and Health Sciences, Hawassa University, Ethiopia
}

Correspondence should be addressed to Birkneh Tilahun Tadesse; birknehtilahun@gmail.com

Received 8 October 2020; Revised 19 November 2020; Accepted 25 November 2020; Published 2 December 2020

Academic Editor: Cem Karadeniz

Copyright (c) 2020 Asnakech Agegnehu et al. This is an open access article distributed under the Creative Commons Attribution License, which permits unrestricted use, distribution, and reproduction in any medium, provided the original work is properly cited.

\begin{abstract}
Background. Over the past decade, drug resistance pattern has worsened for many of the uropathogens due to overuse of antibiotics for empiric treatment. The burden of extended spectrum beta-lactamase (ESBL) producing Enterobacteriaceae associated urinary tract infections (UTI) has become increasingly more common, limiting treatment options among children presenting with febrile UTI. We investigated the burden and correlates of ESBL producing Enterobacteriaceae associated UTI among children and antibacterial resistance pattern. Methods. 284 midstream urine specimens were collected using standard aseptic techniques from 284 children who were diagnosed with suspected UTI. Urine culture and bacteria isolation were performed following standard bacteriological techniques. The Kirby-Bauer disk diffusion technique and the double-disc synergy test were used to investigate antibiotic susceptibility and presence of ESBL production. Results. UTI was confirmed using a positive urine culture for a relevant pathogen in $96 / 284$ (33.8\%) of the cases. Enterobacteriaceae accounted for $75 \%$ (72/96) of etiologies of UTI in children. The most frequent Enterobacteriaceae spp. were E. coli, 44.4\% (32/72) and K. pneumonia, 27.8\% (20/72). The overall multidrug resistance rate was 86.1\% (62/72). ESBL-producers accounted for 41.7\% (30/72) of the isolated Enterobacteriaceae. ESBL producing K. pneumonia and E. coli isolates accounted for $70 \%(14 / 20)$ and $37.5 \%(12 / 32)$, respectively. History of UTI in the past 1 year (adjusted odds ratio $(\mathrm{AoR})=0.08,95 \% \mathrm{CI}(0.01-0.57)$ ) and medium family wealth index (AoR $=0.03,95 \% \mathrm{CI}(0.00-0.27)$ ) protected from infection with ESBL-producing Enterobacteriaceae. Conclusion. ESBL production was more common in $K$. pneumonia and appeared to be a major factor contributing drug resistance UTI in children. The findings call for the need to incorporate ESBL testing in the routine clinical practice. The resistance level to commonly prescribed first-line antibiotics observed within Enterobacteriaceae was alarming calling for strengthened antimicrobial stewardship.
\end{abstract}

\section{Introduction}

Urinary tract infection (UTI), which is commonly caused by Enterobacteriaceae like Escherichia coli (E. coli) and Klebsiella species and other Gram-negative bacteria, is one of the commonest causes of febrile illnesses in children $[1,2]$. Extended spectrum $\beta$-lactamase (ESBL) producing Enterobacteriaceae causing UTI have been associated with prescription of broad-spectrum antibiotics, which further exacerbate the challenge of antimicrobial resistance (AMR) [3].

In several settings, the occurrence of ESBL-producing bacterial infections like E. coli and Klebsiella species were described as a pandemic $[1,4,5]$. ESBLs are plasmid-mediated enzymes, which confer resistance to Gram-negative bacteria [6], through three mechanisms-first, $\beta$-lactam cannot reach penicillinbinding proteins (PBP); second, decreased affinity to PBPs; 
and third, $\beta$-lactamases destroy the drug [7]. $\beta$-lactamase enzymes destroy inactivate $\beta$-lactam containing antibiotics, and ESBLs contain serine. These enzymes can hydrolyze penicillin, cephalosporin, aztreonam, and monobactam antibiotics making them ineffective. Cephamycin groups including cefoxitin and cefotetan and carbapenems including imipenem, meropenem, and ertapenem are not hydrolyzed by ESBLs and are hence considered as the drugs of choice for treating ESBLproducing Enterobacteriaceae [8]. However, these drugs are not readily available; and, in settings where diagnostics for ESBL producing Enterobacteriaceae are limited, targeting treatment becomes a challenge.

Circulation of ESBL-producing Enterobacteriaceae in the community and healthcare settings is a significant global challenge as this could be associated with increasing trends of AMR, which is even more significant in the sub-Saharan African region [9]. Furthermore, high levels of AMR related to ESBL-producing Enterobacteriaceae complicate individual patient care increasing the mortality and morbidity associated with common infectious diseases in children like UTI [10]. Of note, the alarming AMR trend is partly due to the irrational use of antibiotics in resource-limited settings which further leads to more selective pressure drug resistance $[7,11]$.

There is limited data on the extent of infections among children caused by ESBL-producing Enterobacteriaceae. We investigated the prevalence and correlates of pediatric UTI caused by ESBL-producing Enterobacteriaceae at a tertiary hospital. The findings will have a critical importance to guide empiric use of antibiotics in the pediatric population in the setting. It will also shed light on the importance of routine testing for ESBL-production in pediatric urine samples.

\section{Methods and Materials}

2.1. Study Setting and Participants. A cross-sectional study was conducted from February 1, 2018, to July 30, 2018, among children presenting to the outpatient department of Hawassa Comprehensive Specialized Hospital, which is a tertiary referral facility in southern Ethiopia.

Included were children below the age of 15 years with clinically suspected UTI defined as those with at least one of the signs and symptoms of urinary tract infection including frequency, urgency, dysuria, abdominal pain, back pain, and fever $\left(>38.0^{\circ} \mathrm{C}\right)$. Participants who received antibiotics within two weeks before presentation to the hospital were excluded.

2.2. Sample Size. Sample size was calculated using singlepopulation proportion formulae considering the prevalence of extended spectrum $\beta$-lactamase (ESBL) producing Enterobacteriaceae of $78.6 \%$ [12]. Using survey methods, $10 \%$ nonresponse rate and $95 \%$ confidence interval, a final sample size of 284 subjects with suspected UTI was estimated.

\subsection{Data Collection}

2.3.1. Sociodemographic and Clinical Data. Sociodemographics including age (years), sex, residence, parental education and occupation, living standard, and clinical history of participants such as hospital admission and history of UTI within the past 12 months were recorded.
2.3.2. Laboratory Data Collection. A total of 284 early morning midstream (MSU) and catheterized urine samples were collected using properly labelled sterile, clean, transparent, screw-capped, wide-mouth plastic cups. Samples were transported to the microbiology laboratory within two hours of collection. Standard wire loop of $1 \mu \mathrm{l}$ diameter was used to inoculate approximately $0.001 \mathrm{~mL}$ urine on $5 \%$ sheep Blood agar (OXOID Ltd. England) and MacConkey agar (OXOID Ltd., Basingstoke, United Kingdom) plate which were incubated aerobically at $37^{\circ} \mathrm{C}$ for $24 \mathrm{hrs}$.

Significant bacterial growth was determined on Blood agar plate when a single midstream or catheterized urine culture yields $>10^{5} \mathrm{CFU} / \mathrm{mL}$ [13]. Macroscopic examination for hemolysis, changes in physical appearance on differential media, and colony characteristics were recorded to help in identification. Furthermore, Gram reaction, morphology, and colony arrangement were recorded. Biochemical tests including Indole production, sugar fermentation, $\mathrm{H}_{2} \mathrm{~S}$ and gas production, citrate utilization, motility test, mannitol test, and urease and oxidase test were also done to further identify Enterobacteriaceae isolates. If not processed immediately, we kept the isolated bacteria at $2-8^{\circ} \mathrm{C}$ in a nutrient broth for not more than $24 \mathrm{hrs}$ until the antimicrobial sensitivity test was done.

2.4. Detection and Confirmation of ESBL Producing Enterobacteriaceae. Standard disc diffusion method was used to assess ESBL production among isolated Enterobacteriaceae which was then confirmed by the double-disc synergy test (DDST) using third-generation cephalosporins and modified double-disc synergy test using cefepime along with the third-generation cephalosporins, following standard microbiological procedures and the Clinical and Laboratory Standards Institute (CLSI) guidelines [14].

2.5. Procedures for Double-Disc Synergy Test (DDST). Antibiotic discs of $20 / 10 \mu \mathrm{g}$ of amoxicillin/clavulanic acid centrally and $30 \mu \mathrm{g}$ each of cefotaxime and ceftazidime were placed center to center at $15 \mathrm{~mm}$ apart, followed by incubation at $37^{\circ} \mathrm{C}$ for $18-24$ hours. ESBL production was considered when inhibition zones of cefotaxime and ceftazidime extending towards clavulanic acid disc. Modified double-disc synergy test using Cefepime antibiotic disc was used to further detect AMPC lactamase coproducing false-negative isolates.

2.6. Procedures for Modified Double-Disc Synergy Test (MDDST). Similar concentrations of amoxicillin-clavulanate antibiotic disc with cephalosporins namely ceftriaxone, cefotaxime, cefepime, and ceftazidime are used in MDDST. Any distortion or increase in the zone of inhibition of the cephalosporin discs towards the amoxicillin-clavulanate disc was considered as confirmatory for ESBLs production.

2.7. Antimicrobial Susceptibility Testing. Kirby-Bauer disk diffusion method was used to assess antimicrobial susceptibility as recommended by the CLSI guidelines [13, 14]. Ampicillin (AMP: $10 \mu \mathrm{g}$ ), ciprofloxacin (CEP: $30 \mu \mathrm{g}$ ), nitrofurantoin (NIF: $300 \mu \mathrm{g}, \mathrm{BD}$ ), norfloxacin (NOR: $10 \mu \mathrm{g}$ ), amoxicillinclavulanic acid (AMC: 20/10 $\mu \mathrm{g}$ ), gentamicin (G: $10 \mu \mathrm{g}$ ), trimethoprim-sulfamethoxazole (STX: $1.25 / 23.75 \mu \mathrm{g}$ ) cefotaxime (CTX: $30 \mu \mathrm{g}$ ), cefoxitin (FOR: $30 \mu \mathrm{g}$ ), ceftriaxone (CTR: 
TABLE 1: Demographic and clinical characteristics of study participants among UTI suspected children ( $<15$ years) at HUCSH from February 1 to July 30, 2018, Hawassa, Ethiopia.

\begin{tabular}{|c|c|c|c|}
\hline Variables & Category & Number & Percentage \\
\hline \multirow{3}{*}{ Age } & $0-4$ years & 159 & 56.0 \\
\hline & $5-9$ years & 61 & 21.5 \\
\hline & $10-14$ & 64 & 22.5 \\
\hline \multirow{2}{*}{ Sex } & Male & 149 & 52.5 \\
\hline & Female & 135 & 47.5 \\
\hline \multirow{2}{*}{ Place of residence } & Urban & 174 & 61.3 \\
\hline & Rural & 110 & 38.7 \\
\hline \multirow{2}{*}{ Patient type } & Outpatient & 134 & 47.2 \\
\hline & Inpatient & 150 & 52.8 \\
\hline \multirow{2}{*}{ Malnourished } & Yes & 57 & 20.1 \\
\hline & No & 227 & 79.9 \\
\hline \multirow{2}{*}{ Hospital admission within the past 12 months } & Yes & 96 & 33.8 \\
\hline & No & 188 & 66.2 \\
\hline \multirow{2}{*}{ Surgery within the past 6 months* } & Yes & 28 & 9.9 \\
\hline & No & 256 & 90.1 \\
\hline \multirow{2}{*}{ UTI within the past 12 months } & Yes & 40 & 14.1 \\
\hline & No & 244 & 85.9 \\
\hline \multirow{3}{*}{ Paternal education } & No education & 78 & 27.5 \\
\hline & Primary & 87 & 30.6 \\
\hline & Secondary and above & 119 & 41.9 \\
\hline \multirow{3}{*}{ Maternal education } & No education & 109 & 38.4 \\
\hline & Primary & 87 & 30.6 \\
\hline & Secondary and above & 88 & 31.0 \\
\hline \multirow{4}{*}{ Paternal occupation } & Employed & 125 & 44.0 \\
\hline & Merchant & 46 & 16.2 \\
\hline & Farmer & 82 & 28.9 \\
\hline & Daily laborers & 31 & 10.9 \\
\hline \multirow{3}{*}{ Maternal occupation } & Housewife & 173 & 60.9 \\
\hline & Employed & 61 & 21.5 \\
\hline & Merchant & 50 & 17.6 \\
\hline
\end{tabular}

$30 \mu \mathrm{g}$ ), tetracycline (TE: $30 \mu \mathrm{g}$ ), and meropenem (MEM: $10 \mu \mathrm{g})$. Zone of inhibition was measured after overnight incubation at $37^{\circ} \mathrm{C}$. Nonsusceptibility to three or more classes of antibiotics defined multidrug resistance.

2.8. Data Analysis. Descriptive data were presented as frequency (percentage), mean (standard deviation), median (range), and using tables and figures. Predictors of infection with ESBL producing Enterobacteriaceae were assessed using bivariate logistic regression. Multivariate logistic regression models were run using all variables with a $\boldsymbol{P}$ value $<0.25$ in univariate analysis. Covariates with a $\boldsymbol{P}$ value of $<0.05$ in the multivariate models were considered as independent predictors of infection with ESBL producing bacteria. Anthropometric $Z$-scores were generated using WHO Anthro plus, while family wealth status was assessed using principal component analysis (PCA).
2.9. Ethical Considerations. The study received ethical approval from the institutional review board (IRB) of Hawassa University (IRB Number: IRB/156/10). Written informed assent was obtained from study participants or caretakers of children. Patient privacy was protected by deidentification of records. Names of patients were coded. All data obtained during the study were kept confidential and were used solely for the purpose of the study. Positive laboratory result from the study participant was communicated to their physicians for appropriate treatment or management.

\section{Results}

3.1. Demographic and Clinical Characteristics. A total of 284 children $\leq 14$ years of age were included in the study. Of the total study participants, $52.46 \%(149 / 284)$ were male, $61.3 \%$ (174/284) were urban residents, 52.8\% (150/284) were 
TABLE 2: Frequency of ESBL producer and non-ESBL producer Enterobacteriaceae isolated from children suspected of UTI at HUCSH from February 1 to July 30, 2018, Hawassa, Ethiopia.

\begin{tabular}{|c|c|c|c|c|c|c|c|c|c|}
\hline & $\begin{array}{c}\text { K. pneumonia } \\
\text { No }(\%)\end{array}$ & $\begin{array}{c}\text { E. coli } \\
\text { No }(\%)\end{array}$ & $\begin{array}{c}\text { K. Oxytoca } \\
\text { No }(\%)\end{array}$ & $\begin{array}{c}\text { K. Ozaenae } \\
\text { No }(\%)\end{array}$ & $\begin{array}{c}\text { E. cloacae } \\
\text { No }(\%)\end{array}$ & $\begin{array}{c}\text { P. mirabilis } \\
\text { No }(\%)\end{array}$ & $\begin{array}{l}\text { C. diversus } \\
\text { No }(\%)\end{array}$ & $\begin{array}{c}\text { Providencia spp. } \\
\text { No }(\%)\end{array}$ & Total \\
\hline ESBL-producer & $14(70)$ & $12(37.5)$ & $3(50)$ & $1(33.3)$ & $0(0.0)$ & $0(0.0)$ & $0(0.0)$ & $0(0.0)$ & $30(41.7)$ \\
\hline Non-ESBL producer & $6(30)$ & $20(62.5)$ & $3(50)$ & $2(66.7)$ & $2(100)$ & $2(100)$ & $3(100)$ & $4(100)$ & $42(58.3)$ \\
\hline Total & $20(100)$ & $32(100)$ & $6(100)$ & $3(100)$ & $2(100)$ & $2(100)$ & $3(100)$ & $4(100)$ & $72(100)$ \\
\hline
\end{tabular}

treated as inpatient, $20.1 \%(57 / 284)$ had malnutrition, and $9.9 \%(28 / 284)$ underwent surgical procedures in the past 6 months. Subjects with a history of hospital admission and UTI within the past 12 months accounted for $33.8 \%$ $(96 / 284)$ and $14.1 \%(40 / 284)$, respectively (Table 1$)$.

3.2. Frequency of Enterobacteriaceae Isolates. From 284 urine specimens, growth was detected in 90 specimens, and a total of $96(33.8 \%)$ bacterial species were identified. Among these, $75 \%(n=72 / 96)$ were Enterobacteriaceae with E. coli $(44.4 \%$, $n=32 / 72)$, K. pneumonia $(27.8 \%, n=20 / 72)$, Klebsiella oxytoca $(8.33 \%, n=6 / 72)$, Providencia spp. (5.6\%, $n=4 / 72)$, Citrobacter diversus $(4.16 \%, n=3 / 72)$, Enterobacter cloacae $(2.8 \%, n=2 / 72)$, Proteus mirabilis $(2.8 \%, n=2 / 72)$, and Klebsiella ozaenae $(4.16 \%, n=3 / 72)$ being most common isolates. The remaining 25\% (24/96) from the non-Enterobacteriaceae group were Pseudomonas spp. (3.12\%, $n=3 / 96)$, Enterococcus spp. $(11.5 \%, n=11 / 96), S$. aureus $(5.21 \%, n=5 / 96), S$. saprophyticus $(3.12 \%, n=3 / 96)$, and yeast cell $(2.1 \%, n=2$ / 96) (Table 2).

Enterobacteriaceae were more commonly isolated among female subjects $(55.6 \%, n=40 / 72)$ than male subjects $(41.7 \%$, $n=30 / 72)(P$ value $=0.07)$. Furthermore, Enterobacteriaceae were isolated from study subjects who attended inpatient department $(59.7 \%, 43 / 72)$, urban $(58.3 \%, 42 / 72)$, and aged less than four years $(54.2 \%, 39 / 72)$. Klebsiella species, $25 \%$ (18/72), and E. coli, $16.7 \%(12 / 72)$, were the most frequently isolated Enterobacteriaceae (Table 2 and Figure 1).

3.3. Prevalence and Predictors of ESBL Producing Enterobacteriaceae. Potentially ESBL producing Enterobacteriaceae accounted for $58.3 \%$ (42/72) of the total isolates, of which $71.4 \%$ (30/42) were confirmed as ESBL producers.

We then performed bivariate analysis using paternal occupation, maternal education, paternal education, age, place of residence, patient type, history of UTI within the past 12 months, and family wealth index against ESBL infection. Next, we pooled the variables with a $P$ value $<0.025$ to identify independent predictors of infection with ESBL producing Enterobacteriaceae. Children with a history of UTI within the past 12 months were less likely to be infected with ESBL producing Enterobacteriaceae (AOR $=0.076$ with $95 \%$ CI $(0.010$ $0.569)$. Family wealth index of medium was associated with lower risk of infection by ESBL-producing Enterobacteriaceae as compared to those with poor family wealth index $(\mathrm{AOR}=0.029$ with $95 \% \mathrm{CI}(0.003-0.265)$ (Table 3$)$.

3.4. Antibiotic Resistance Profile of Isolated Enterobacteriaceae. The antibiotics resistance profile of Enterobacteriaceae isolated

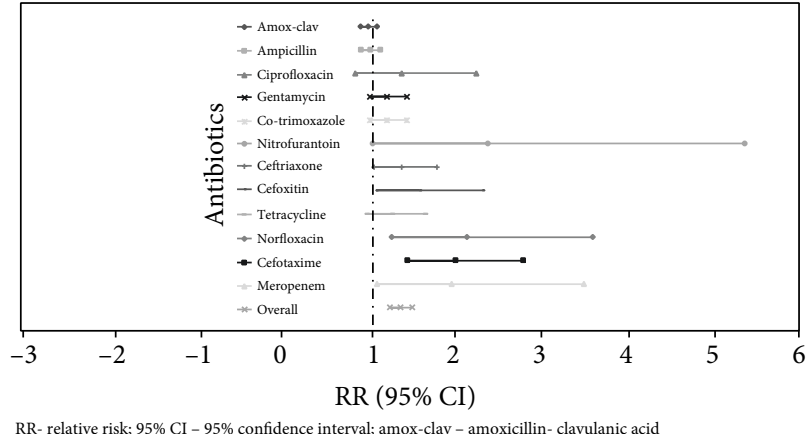

FIGURE 1: Relative risk of antibiotic resistance in ESBL producers as compared to nonproducers. RR: relative risk; 95\% CI: 95\% confidence interval; Amox-Clav: amoxicillin-clavulanic acid.

in urine specimen against 12 antibiotics is presented in Tables 4-6. Majority of isolates were resistant to ampicillin (95.8\%), amoxicillin/clavulanic acid (94.4\%), trimethoprimsulfamethoxazole (86.1\%), and gentamycin (86.1\%), while better susceptibility was observed for ciprofloxacin (47.2\%), norfloxacin (45.8\%), meropenem (40.3\%), and nitrofurantoin (26.4\%). Of the 72 Enterobacteriaceae isolates tested for antibiotic susceptibility testing, $62(86.1 \%)$ were nonsusceptible to three or more drugs belonging to different antibiotics classes. Four $(5.6 \%)$ of the isolates were nonsusceptible to all antibiotics tested. From ESBL-producing Enterobacteriaceae, 96.7\% were multidrug resistant.

3.5. Drug Resistance of ESBL-Producing Enterobacteriaceae. ESBL-producing Enterobacteriaceae were resistant to amoxicillin/clavulanic acid (96.7\%), ampicillin (96.7\%), trimethoprim-sulfamethoxazole (96.7\%), gentamycin (96.7\%), cefotaxime (96.7\%), ceftriaxone (90\%), and tetracycline $(86.7 \%)$ as compared to ESBL non-producers (Table 6). Except for amoxicillin-clavulanic acid, ampicillin, and ciprofloxacin, the odds of resistance to all other tested antibiotics was significantly higher among ESBL producing Enterobacteriaceae as compared to nonproducers (Figure 1).

\section{Discussion}

Our findings show that urine culture growth was observed in a third of cases presenting with clinically suspected cases of UTI. The majority of bacterial isolates identified in the culture were Gram-negative bacteria, a finding comparable to findings from another tertiary care hospital in Ethiopia [12]. The culture confirmation rate of suspected cases in the current study higher than studies elsewhere $[10,15,16]$, reflecting the variability in clinical index of suspicion and 
TABLE 3: Bivariate and multivariable analysis of independent variables against ESBL production status among UTI suspected children $(<15$ years) at HUCSH from February 1, 2018, to July 30, 2018, Hawassa, Ethiopia.

\begin{tabular}{|c|c|c|c|c|c|c|}
\hline Variable & Category & $\begin{array}{c}\text { ESBL } \\
\text { producer }\end{array}$ & $\begin{array}{c}\text { ESBL } \\
\text { nonproducer }\end{array}$ & COR $(95 \% \mathrm{CI})$ & AOR $(95 \% \mathrm{CI})$ & $\begin{array}{c}P \\
\text { value }\end{array}$ \\
\hline \multirow{3}{*}{ Age } & $0-4$ & 11 & 28 & 1 & 1 & \\
\hline & $5-9$ & 7 & 8 & $0.449(0.131-1.538)$ & $0.506(0.078-3.261)$ & 0.473 \\
\hline & $10-14$ & 12 & 6 & $0.196(0.059-0.654)$ & $0.183(0.029-1.157)$ & 0.071 \\
\hline \multirow[b]{2}{*}{ Place of residence } & Urban & 22 & 20 & 1 & 1 & \\
\hline & Rural & 8 & 22 & $3.025(1.101-8.311)$ & $\begin{array}{c}3.900(0.634-13- \\
984)\end{array}$ & 0.142 \\
\hline \multirow[b]{2}{*}{ Patient type } & Outpatient & 16 & 13 & 1 & 1 & \\
\hline & Inpatient & 14 & 29 & $2.549(0.966-6.731)$ & $\begin{array}{c}2.546(0.433-14- \\
958)\end{array}$ & 0.301 \\
\hline \multirow{2}{*}{$\begin{array}{l}\text { UTI within the past } 12 \\
\text { months }\end{array}$} & No & 20 & 34 & 1 & 1 & \multirow{2}{*}{0.012} \\
\hline & Yes & 10 & 8 & $0.471(0.160-1.388)$ & $0.076(0.010-0.569)$ & \\
\hline \multirow{2}{*}{ Surgery past 6 months } & Yes & 6 & 7 & 1 & \multirow{2}{*}{ NA } & \\
\hline & No & 24 & 35 & $0.800(0.239-2.677)$ & & \\
\hline \multirow{4}{*}{ Paternal occupation } & Employee & 11 & 16 & 1 & 1 & \\
\hline & Merchant & 8 & 4 & $0.344(0.083-1.429)$ & $0.136(0.14-1.324)$ & 0.086 \\
\hline & Farmer & 10 & 15 & $1.031(0.340-3.126)$ & $0.399(0.027-5.815)$ & 0.502 \\
\hline & Daily laborers & 1 & 7 & $\begin{array}{c}4.812(0.517-14- \\
822)\end{array}$ & $2.669(0.149-9.061)$ & 0.328 \\
\hline \multirow{3}{*}{ Maternal occupation } & Housewife & 19 & 25 & 1 & \multirow{3}{*}{ NA } & \\
\hline & Employee & 5 & 6 & $0.912(0.242-3.442)$ & & \\
\hline & Merchant & 6 & 11 & $1.393(0.4374 .444)$ & & \\
\hline \multirow{3}{*}{ Paternal education } & No education & 8 & 18 & 1 & 1 & \\
\hline & Primary & 10 & 12 & $0.533(0.164-1.740)$ & $0.294(0.021-4.080)$ & 0.362 \\
\hline & $\begin{array}{l}\text { Secondary and } \\
\text { above }\end{array}$ & 12 & 12 & $0.444(0.140-1.411)$ & $0.309(0.012-7.908)$ & 0.478 \\
\hline \multirow{3}{*}{ Maternal education } & No education & 10 & 20 & 1 & 1 & \\
\hline & Primary & 12 & 10 & $0.417(0.134-1.292)$ & $0.078(0.003-2.384)$ & 0.144 \\
\hline & $\begin{array}{l}\text { Secondary and } \\
\text { above }\end{array}$ & 8 & 12 & $0.750(0.232-2.424)$ & $\begin{array}{c}0.843(0.020- \\
14.961)\end{array}$ & 0.929 \\
\hline \multirow{3}{*}{ Family wealth index } & Poor & 4 & 10 & 1 & 1 & \\
\hline & Medium & 23 & 19 & $0.330(0.089-1.224)$ & $0.029(0.003-0.265)$ & 0.002 \\
\hline & Rich & 3 & 13 & $1.733(0.314-9.573)$ & $\begin{array}{c}2.984(0.144- \\
12.696)\end{array}$ & 0.479 \\
\hline
\end{tabular}

COR: crude odds ratio; AOR: adjusted odds ratio, ${ }^{*} P$ value $<0.05$, NA: not applicable, which is the variable did not meet criterion $(P$ value $<0.25)$ to be included in multivariate analysis.

the healthcare settings. Important limitations of the current study include that certain clinical features such as ICU admission and circumcision (for boys) were not assessed as potential factors for infection with ESBL producing Enterobacteriaceae. Molecular epidemiological characterization of ESBL producing Enterobacteriaceae was not possible.

The prevalence of ESBLs producers within the Enterobacteriaceae in the study was $41.7 \%$, which is similar to findings in Ethiopia (38.0-51\%) [17, 18], Nigeria (47.1\%) [19], and India (38.2\%) [20]. However, the prevalence of ESBL production in the current study is much lower than that reported from a study at a tertiary facility in Ethiopia [12], which included Enterobacteriaceae from specimens other than urine and reported a much smaller number of isolates. The
ESBL prevalence was also lower than those reported in Burkina Faso 58\%, from clinical samples [21] and Nepal $62.31 \%$ from urinary isolates [22], both of which included adults. On the other hand, the prevalence of ESBL observed in our study was higher than another study in Ethiopia (25\%) [23], and studies in Morocco (25.5\%) [24], Iran (28.4\%) [25], and Korea (16.7\%) [26]. The higher prevalence seen in our study compared to developed countries like Greece (10.4\%) [27] could be attributed to differences in infection control policies and practices, duration of hospitalization, and improved nursing barriers that decrease acquisition and spread of ESBL producing strains.

Similar to previous reports, E. coli was the most common cause of UTI followed by K. pneumonia [18, 28, 29]. Even 
TABLe 4: Antibacterial resistance levels of Enterobacteriaceae isolated from children ( $<15$ years) suspected of UTI in pediatric department at HUCSH from February 1 to July 30, 2018, Hawassa, Ethiopia.

\begin{tabular}{|c|c|c|c|c|c|c|c|c|c|c|c|c|c|}
\hline \multirow[t]{2}{*}{$\begin{array}{l}\text { Organism } \\
\text { isolated }\end{array}$} & \multirow[t]{2}{*}{$N$} & \multicolumn{12}{|c|}{ Antibiotics tested } \\
\hline & & AMC & AMP & CIP & GEN & STX & NIF & CTR & FOX & TET & NOR & CXT & MEM \\
\hline K. pneumonia & 20 & $19(95)$ & $19(95)$ & $7(35)$ & $17(85)$ & $17(85)$ & $7(35)$ & $17(85)$ & $11(55)$ & $17(85)$ & $8(40)$ & $15(75)$ & $11(55)$ \\
\hline E. coli & 32 & $\begin{array}{c}30 \\
(93.8)\end{array}$ & $\begin{array}{c}29 \\
(90.6)\end{array}$ & $\begin{array}{c}20 \\
(62.5)\end{array}$ & $\begin{array}{c}28 \\
(87.5)\end{array}$ & $\begin{array}{c}29 \\
(90.6)\end{array}$ & $5(15.6)$ & $\begin{array}{c}22 \\
(68.8)\end{array}$ & $\begin{array}{c}22 \\
(68.8)\end{array}$ & $24(75)$ & $\begin{array}{c}19 \\
(59.4)\end{array}$ & $\begin{array}{c}20 \\
(62.5)\end{array}$ & $6(18.8)$ \\
\hline K. ozaenae & 3 & $3(100)$ & $3(100)$ & $0(0)$ & $3(100)$ & $2(66.7)$ & $1(33.3)$ & $3(100)$ & $1(33.3)$ & $3(100)$ & $0(0)$ & $2(66.7)$ & $2(66.7)$ \\
\hline K. oxytoca & 6 & $6(100)$ & $6(100)$ & $4(66.7)$ & $5(83.3)$ & $6(100)$ & $4(66.7)$ & $5(83.3)$ & $2(33.3)$ & $\begin{array}{c}4 \\
(66.7)\end{array}$ & $2(33.3)$ & $5(83.3)$ & $4(66.7)$ \\
\hline E. cloacae & 2 & $2(100)$ & $2(100)$ & $1(50)$ & $2(100)$ & $2(100)$ & $0(0)$ & $1(50)$ & $1(50)$ & $1(50)$ & $0(0)$ & $1(50)$ & $0(0)$ \\
\hline P. mirabilis & 2 & $2(100)$ & $2(50)$ & $0(0)$ & $2(100)$ & $2(100)$ & $0(0)$ & $0(0)$ & $2(100)$ & $1(50)$ & $1(50)$ & $0(0)$ & $0(0)$ \\
\hline C. diversus & 3 & $3(100)$ & $3(100)$ & $1(33.3)$ & $2(66.7)$ & $2(66.7)$ & $0(0)$ & $2(66.7)$ & $2(66.7)$ & $\begin{array}{c}2 \\
(66.7)\end{array}$ & $2(66.7)$ & $2(66.7)$ & $2(66.7)$ \\
\hline Providencia spp. & 4 & $4(100)$ & $4(100)$ & $1(25)$ & $3(75)$ & $2(50)$ & $2(50)$ & $4(100)$ & $2(50)$ & $2(50)$ & $1(25)$ & $3(75)$ & $4(100)$ \\
\hline Total & 72 & $\begin{array}{c}69 \\
(95.8)\end{array}$ & $\begin{array}{c}68 \\
(94.4)\end{array}$ & $\begin{array}{c}34 \\
(47.2)\end{array}$ & $\begin{array}{c}62 \\
(86.1)\end{array}$ & $\begin{array}{c}62 \\
(86.1)\end{array}$ & $\begin{array}{c}19 \\
(26.4)\end{array}$ & $54(75)$ & $\begin{array}{c}43 \\
(59.7)\end{array}$ & $54(75)$ & $\begin{array}{c}33 \\
(45.8)\end{array}$ & $49(68)$ & $\begin{array}{c}29 \\
(40.3)\end{array}$ \\
\hline
\end{tabular}

Abbreviations: AMC: amoxacillin/clavulanate; AMP: ampicillin; CIP: ciprofloxacin; GN: gentamicin; STX: trimethoprim-sulfamethoxazole; NIF: nitrofurantoin; CTR: ceftriaxone; FOX: cefoxitin; TET: tetracycline; NOR: norfloxacin; CXT: cefotaxime; MEM: meropenem.

TABLE 5: Multidrug resistance level of Enterobacteriaceae isolated from children ( $<15$ years) suspected of UTI in pediatric department at HUCSH from February 1 to July 30, 2018, Hawassa, Ethiopia.

\begin{tabular}{lccccccccc}
\hline & \multicolumn{3}{c}{ Level of antibiotics resistance (number (\%)) } & \multicolumn{3}{c}{$\begin{array}{c}\text { Total MDR-E } \\
(>\mathrm{R} 3)\end{array}$} \\
Isolates (number) & $\mathrm{R} 0$ & $\mathrm{R} 1$ & $\mathrm{R} 2$ & $\mathrm{R} 3$ & $\mathrm{R} 4$ & $\mathrm{R} 5$ & $\mathrm{R} 6$ & $\mathrm{R} 7$ \\
\hline E. coli (32) & $0(0.0)$ & $1(3.1)$ & $2(6.3)$ & $8(25)$ & $7(21.9)$ & $7(21.9)$ & $4(12.5)$ & $3(9.4)$ & $29(90.6)$ \\
K. pneumonea (20) & $0(0.0)$ & $1(5.0)$ & $2(10.0)$ & $8(40.0)$ & $4(20.0)$ & $3(15.0)$ & $1(5.0)$ & $1(5.0)$ & $17(85.0)$ \\
K. ozaenae (3) & $0(0.0)$ & $0(0.0)$ & $0(0.0)$ & $2(66.7)$ & $0(0.0)$ & $0(0.0)$ & $1(33.3)$ & $0(0.0)$ & $3(100)$ \\
K. oxytoca (6) & $0(0.0)$ & $1(16.7)$ & $1(16.7)$ & $1(16.7)$ & $0(0.0)$ & $2(33.3)$ & $0(0.0)$ & $1(16.7)$ & $4(66.7)$ \\
E. cloacae (2) & $0(0.0)$ & $0(0.0)$ & $0(0.0)$ & $1(50.0)$ & $1(50.0)$ & $0(0.0)$ & $0(0.0)$ & $0(0.0)$ & $2(100)$ \\
Citrobacter diversus (3) & $0(0.0)$ & $0(0.0)$ & $0(0.0)$ & $0(0.0)$ & $1(33.3)$ & $0(0.0)$ & $1(33.3)$ & $0(0.0)$ & $2(66.7)$ \\
P. mirabilis (2) & $0(0.0)$ & $0(0.0)$ & $0(0.0)$ & $0(0.0)$ & $1(50.0)$ & $1(50.0)$ & $0(0.0)$ & $0(0.0)$ & $2(100)$ \\
Providencia spp. (4) & $0(0.0)$ & $1(25.0)$ & $0(0.0)$ & $1(25.00$ & $0(0.0)$ & $2(50.0)$ & $0(0.0)$ & $0(0.0)$ & $3(75.0)$ \\
Total (72) & & & & & & & & $62(86.1)$ \\
\hline
\end{tabular}

though E. coli had high isolation rate (44.4\%) in the study, Klebsiella spp. was identified as the major ESBL producer $25 \%$ (18/72) followed by E. coli $16.7 \%$ (12/72). A similar trend was reported by studies in Ethiopia and Pakistan [17, 30], while more ESBL production in E. coli as compared to K. pneumonia in another study in Ethiopia [12].

A worrying level of multidrug resistance was reported in our study which adds to previous reports in other facilities in Ethiopia, for example, $87.4 \%$ in Northwest Ethiopia [1] and 68.3\% in Addis Ababa, Ethiopia [18]. Studies elsewhere also reported similarly high isolation rates of multidrug-resistant bacteria, for instance in Chicago, USA, 76\% [31], Nepal $64.04 \%$ [32], and Iran 52.7\% [29]. Unsurprisingly, ESBLproducing Enterobacteriaceae are associated with multidrug resistance in nearly all the cases (96.7\%) - a finding very close to another survey in Addis Ababa, Ethiopia, with 96.3\% multidrug resistance [18]. Nitrofurantoin demonstrated a lower level of resistance among E. coli and K. pneumoniae isolates, favoring the use of this antibiotic for empiric treatment of UTI in children. The lower resistance levels could point to the lower utilization of the antibiotic [33]. Our finding together with similar previous studies underscore the contribution of ESBL producing Enterobacteriaceae spp in multidrug resistance outbreaks in healthcare facilities. The findings call for an urgent assessment of the national burden of ESBL-producing Enterobacteriaceae which cause UTI and other clinical diseases including the antimicrobial susceptibility patterns. Such efforts would have paramount importance to guide local treatment and care guidelines.

Antibiotic resistance levels of Enterobacteriaceae are reported to be high in several resource-limited settings. For example, in Iran, resistance to trimethoprim-sulfamethoxazole (93.6\%), ciprofloxacin (40.4\%), and tetracycline (84.5\%) [29] was reported. Similarly, in Bangladesh, $97.8 \%$ for trimethoprim-sulfamethoxazole 
TABLE 6: Antibacterial resistance levels of ESBL-producing and non-ESBL-producing Enterobacteriaceae among UTI-suspected children ( $<15$ years) at HUCSH from February 1 to July 30, 2018, Hawassa, Ethiopia.

\begin{tabular}{lccc}
\hline Drugs & $\begin{array}{c}\text { ESBL producer (30) } \\
n \text { (\% of NS } *)\end{array}$ & $\begin{array}{c}\text { ESBL } \\
\text { nonproducer (42) } \\
n \text { (\% of NS) }\end{array}$ & $\begin{array}{c}P \\
\text { value }\end{array}$ \\
\hline $\begin{array}{l}\text { Amoxicillin- } \\
\text { clavulanic acid }\end{array}$ & $29(96.7)$ & $40(95.2)$ & 0.63 \\
Ampicillin & $29(96.7)$ & $39(92.9)$ & 0.44 \\
Ciprofloxacin & $17(56.7)$ & $17(40.5)$ & 0.13 \\
Gentamycin & $29(96.7)$ & $33(78.6)$ & 0.028 \\
Co-trimoxazole & $29(96.7)$ & $33(78.6)$ & 0.028 \\
Nitrofurantoin & $12(40)$ & $7(16.7)$ & 0.026 \\
Ceftriaxone & $27(90)$ & $27(64.3)$ & 0.012 \\
Cefoxitin & $23(76.7)$ & $20(47.6)$ & 0.012 \\
Tetracycline & $26(86.7)$ & $28(66.7)$ & 0.047 \\
Norfloxacin & $20(66.7)$ & $13(30.9)$ & 0.003 \\
Cefotaxime & $29(96.7)$ & $20(47.6)$ & $<.0001$ \\
Meropenem & $17(56.7)$ & $12(28.6)$ & 0.012 \\
\hline
\end{tabular}

NS*: nonsusceptible.

was reported [34]. These figures are considerably lower in high-income countries, for example, in the United States, resistance to ampicillin (55\%), amoxicillin/clavulanic acid (10\%), trimethoprim-sulfamethoxazole (24\%), and nitrofurantoin (14\%) of Enterobacteriaceae was reported [31]. These findings present a concerning public health problem, which requires a coordinated action to generate more data in understanding the magnitude of the problem and designing interventions that help to mitigate the issue.

\section{Conclusion}

Our research finding evidenced that ESBL-producing bacteria are prevalent among children with UTI. From the total bacteria species isolated, Enterobacteriaceae contributed to the majority of the isolates. Most of the Enterobacteriaceae were isolated from patients who attended inpatient department. ESBL-producing Klebsiella species were the most frequent Enterobacteriaceae followed by E. coli. Majority of Enterobacteriaceae had resistance to commonly prescribed antibiotics. The drug with preserved efficacy for ESBL producers and non-ESBL producers is nitrofurantoin.

\section{Data Availability}

Data can be provided by the principal investigator upon reasonable request.

\section{Conflicts of Interest}

The authors declare that they have no competing interests.

\section{Authors' Contributions}

AA conceived the study, analyzed and interpreted the data, and prepared the manuscript draft. BTT guided the analysis, interpreted the data, and helped in drafting the manuscript. MW and DN conceived the study and helped during analysis, and BL helped during analysis.

\section{Acknowledgments}

We would like to thank Hawassa University College of Medicine and Health Sciences for technical support. An earlier version of this work has been presented as a preprint: https://www.researchsquare.com/article/rs-11485/v1.

\section{References}

[1] S. Eshetie, C. Unakal, A. Gelaw, B. Ayelign, M. Endris, and F. Moges, "Multidrug resistant and carbapenemase producing Enterobacteriaceae among patients with urinary tract infection at referral Hospital, Northwest Ethiopia," Antimicrobial Resistance and Infection Control, vol. 4, no. 1, 2015.

[2] T. Gezmu, B. Regassa, A. Manilal, and M. Mama, "Prevalence, diversity and antimicrobial resistance of bacteria isolated from the UTI patients of Arba Minch Province, southern Ethiopia," Translational Biomedicine, vol. 7, no. 3, 2016.

[3] Y. H. Kim, E. M. Yang, and C. J. Kim, "Urinary tract infection caused by community-acquired extended-spectrum $\beta$-lactamase-producing bacteria in infants," Jornal de Pediatria, vol. 93, no. 3, pp. 260-266, 2017.

[4] A. Chander and C. D. Shrestha, "Prevalence of extended spectrum beta lactamase producing Escherichia coli and Klebsiella pneumoniae urinary isolates in a tertiary care hospital in Kathmandu, Nepal," BMC Research Notes, vol. 6, no. 1, 2013.

[5] E. Mahesh, D. Ramesh, V. A. Indumathi, M. W. Khan, P. S. Kumar, and K. Punith, "Risk factors for community acquired urinary tract infection caused by ESBI-producing bacteria," Journal, Indian Academy of Clinical Medicine, vol. 11, no. 4, pp. 271-276, 2010.

[6] S. Chandra, "Extended-spectrum beta-lactamase infections," Curr Emerg Hosp Med Rep., vol. 1, no. 3, pp. 145-148, 2013.

[7] CDC, Antibiotic resistance threats in the United States In. U.S. department of health and human services: centers for disease control and prevention, Antibiotic resistance threats in the United States, USA, 2013.

[8] M. E. Rupp and P. D. Fey, "Extended Spectrum??-Lactamase (ESBL)-producing Enterobacteriaceae," Drugs, vol. 63, no. 4, pp. 353-365, 2003.

[9] B. T. Tadesse, E. A. Ashley, S. Ongarello et al., "Antimicrobial resistance in Africa: a systematic review," BMC Infectious Diseases, vol. 17, no. 1, p. 616, 2017.

[10] C. M. Muvunyi, F. Masaisa, A. Musemakweri et al., "Decreased susceptibility to commonly used antimicrobial agents in bacterial pathogens isolated from urinary tract infections in Rwanda: need for new antimicrobial guidelines," The American Journal of Tropical Medicine and Hygiene, vol. 84, no. 6, pp. 923-928, 2011.

[11] K. Desta, Y. Woldeamanuel, A. Azazh et al., "High gastrointestinal colonization rate with extended-spectrum $\beta$-lactamaseproducing Enterobacteriaceae in hospitalized patients: 
emergence of carbapenemase-producing K. pneumoniae in Ethiopia," PLOS ONE, vol. 11, no. 8, article e0161685, 2016.

[12] M. H. Legese, G. Mulugeta, and A. D. Weldearegay, "Extended-spectrum beta-lactamase- and carbapenemaseproducing Enterobacteriaceae among Ethiopian children," Infection and Drug Resistance, vol. Volume 10, pp. 27-34, 2017.

[13] M. Cheesbrough, District Laboratory Practice in Tropical Countries, Published in the United States of America by Cambridge University Press, New York, 2006.

[14] CLSI, Performance Standards for Antimicrobial Susceptibility Testing. In: 27th Edition, CLSI Supplement M100, Wayne, PA, Clinical and Laboratory standards institute, 2017.

[15] B. Abera, M. Kibret, and W. Mulu, "Extended-spectrum beta $(\beta)$-lactamases and Antibiogram in Enterobacteriaceae from clinical and drinking water Sources from Bahir Dar City, Ethiopia," PLOS ONE, vol. 11, no. 11, article e0166519, 2016.

[16] C. M. Ogbukagu, V. N. Anakwenze, C. C. Ekwealor, C. C. Ezemba, and I. A. Ekwealor, "Incidence of urinary tract infections (UTI) amongst patients attending primary health centres in Anambra state," Advances in Microbiology., vol. 6, no. 7, pp. 537-547, 2016.

[17] S. M. Siraj, S. Ali, and B. Wondafrash, "Extended-spectrum $\beta$ lactamase production in Klebsiella pneumoniae and Escherichia coli at Jimma University specialized hospital, south-west," Ethiopia. Molecular Microbiology Research, vol. 5, no. 1, pp. 1-9, 2015.

[18] D. S. Teklu, A. A. Negeri, M. H. Legese, T. L. Bedada, H. K. Woldemariam, and K. D. Tullu, "Extended-spectrum betalactamase production and multi-drug resistance among Enterobacteriaceae isolated in Addis Ababa, Ethiopia," Antimicrobial Resistance and Infection Control, vol. 8, no. 1, 2019.

[19] I. Azekhueme, A. E. Moses, and S. D. Abbey, "Extended spectrum beta-lactamases in clinical isolates of Escherichia coli and Klebsiella pneumoniae from University of Uyo Teaching Hospital, Uyo-Nigeria," Journal of Advances in Medical and Pharmaceutical Sciences, vol. 2, no. 3, pp. 117-125, 2015.

[20] L. Segar, S. Kumar, N. M. Joseph, and U. Sivaraman, "Prevalence of extended spectrum beta-lactamases among Enterobacteriaceae and their anti-biogram pattern from various clinical samples," vol. 8, no. 5, pp. 220-223, 2015, https://innovareacademics.in/ journals/index.php/ajpcr/article/view/7416.

[21] A.-S. Ouedraogo, M. Sanou, A. Kissou et al., "High prevalence of extended-spectrum ß-lactamase producing enterobacteriaceae among clinical isolates in Burkina Faso," BMC Infectious Diseases, vol. 16, no. 1, 2016.

[22] K. Yadav and S. Prakash, "Screening of ESBL producing multidrug resistant E. coli from Urinary tract infection suspected cases in southern Terai of Nepal," Journal of Infectious Diseases and Diagnosis, vol. 2, no. 2, 2017.

[23] L. G. Selassie, "Prevalence of extended spectrum betalactamase producing Enterobacteriaceae: a cross sectional study at Adama Hospital, Adama, Ethiopia," Journal of Emerging Infectious Diseases, vol. 1, no. 1, 2016.

[24] M. C. El Bouamri, L. Arsalane, Y. El Kamouni, and S. Zouhair, "Antimicrobial susceptibility of urinary Klebsiella pneumoniae and the emergence of carbapenem-resistant strains: a retrospective study from a university hospital in Morocco, North Africa," African Journal of Urology, vol. 21, no. 1, pp. 36-40, 2015.

[25] A. Khaledi, D. Esmaeili, K. Esmaeili et al., "Prevalence of extended-spectrum- $\beta$-lactamase-producing Escherichia coli isolates among uropathogensin a pediatrics hospital," Der Pharma Chemica, vol. 8, no. 3, pp. 161-165, 2016.
[26] Y. H. Kima, E. M. Yanga, and C. J. Kima, "Urinary tract infection caused by community-acquired extended-spectrum-lactamase-producing bacteria in infants journal of pediatric," vol. 93, no. 3, pp. 260-266, 2017.

[27] J. Dotis, N. Printza, A. Marneri, D. Gidaris, and F. Papachristou, "Urinary tract infections caused by extended-spectrum beta-lactamase-producing bacteria in children: a matched case-control study," The Turkish Journal of Pediatrics, vol. 55, no. 6, pp. 571-574, 2013.

[28] G. Beyene and W. Tsegaye, "Bacterial uropathogens in urinary tract infection and antibiotic susceptibility pattern in Jimma University Specialized Hospital, Southwest Ethiopia," Ethiopian Journal of Health Science, vol. 21, no. 2, 2011.

[29] S. A. Shahla Mansouri, "Prevalence of multiple drug resistant clinical isolates of extended-spectrum beta-lactamase producing Enterobacteriaceae in Southeast Iran," Iran journal of Medical Sciences, vol. 35, no. 2, pp. 101-108, 2010.

[30] F. I. Afridi, B. J. Farooqi, and A. Hussain, "Frequency of extended spectrum beta lactamase producing enterobacteriaceae among urinary pathogen isolates," Journal of the College of Physicians and Surgeons Pakistan, vol. 21, no. 12, pp. 741744, 2011.

[31] T. Khawcharoenporn, S. Vasoo, and K. Singh, "Urinary tract infections due to Multidrug-Resistant Enterobacteriaceae: prevalence and risk factors in a Chicago Emergency Department," Emergency Medicine International, vol. 2013, 7 pages, 2013.

[32] S. Thakur, N. Pokhrel, and M. Sharma, "Prevalence of multidrug resistant Enterobacteriaceae and extended spectrum $\beta$ lactamase producing Escherichia coli in urinary tract infection," Research Journal of Pharmaceutical, Biological and Chemical Sciences, vol. 4, no. 2, 2013.

[33] B. J. Gardiner, A. J. Stewardson, I. J. Abbott, and A. Y. Peleg, "Nitrofurantoin and fosfomycin for resistant urinary tract infections: old drugs for emerging problems," Australian Prescriber, vol. 42, no. 1, pp. 14-19, 2019.

[34] N. Akhtar, R. Rahman, and S. Sultana, "Antimicrobial sensitivity pattern of Escherichia coli causing urinary tract infection in Bangladeshi patients," American Journal of Microbiological Research, vol. 4, no. 4, 2016. 